the client in a one-stop shop format. However, the natural origin of the concept of ecosystem dictates the use of a different approach based on the interaction within the ecosystem of the subsystem of living and inanimate nature, including humans, and the inorganic environment in the form of a socio-economic subsystem, as a result of which the ecosystem is able to provide society with so-called ecosystem services. Developing the hypothesis of the nature-like essence of social processes in society, the authors put forward the idea that the highest form of ecosystem organization will be a model of a socio-political super ecosystem, or ecosystem of ecosystems, in which the transition to a self-organizing, self-regulating, self-developing ecosystem is realized, created according to the model of a political network. Interdependent ecosystems, organizations and groups of citizens with the coordinating role of the parent provider organization, interact with each other to ensure the achievement of a socially significant strategic priority. In such a super ecosystem, a unified state goal-setting, common moral, ethical and value attitudes of ecosystem actors, along with the possibility of achieving mutual benefit of participants and citizens from socially significant ecosystem activities will allow maintaining a low level of social tension in society, and thereby prevent the emergence of foci of group social polarization.

Keywords: natural ecosystem, social ecosystem, nature-like systems, ecosystem services, social tension, depolarization

НИКОНОВ Владимир Александрович - аспирант Института социологии ФНИСЦ РАН (117218, Россия, г. Москва, ул. Кржижановского, 24/35, корп. 5; nikon561@yandex.ru) ВОРОНОВ Виктор Васильевич - доктор социологическихнаук, профессор; ведущий научный сотрудник Института социологии ФНИСЦ РАН (117218, Россия, г. Москва, ул. Кржижановского, 24/35, кopn. 5; voronov@isras.ru)

\title{
МАЛЫЙ БИЗНЕС МОСКВЫ И ИЗМЕНЕНИЯ ТРУДОВЫХ УСТАНОВОК ЕГО УЧАСТНИКОВ
}

\begin{abstract}
Аннотация. В статье с позиции экономической социологии проведен анализ противоречивости интересов работодателей и наемных работников по отношению к условиям труда в малом бизнесе на примере мегаполиса. Авторы устанавливают ряд неблагоприятных тенденций в сфере трудовых отношений, связанных с низкой заинтересованностью наемных работников в непрестижных видах деятельности, их слабой вовлеченностью в эти отношения при игнорировании их интересов со стороны работодателей. $B$ статье обосновывается необходимость рационального подхода к комплексному процессу формирования кадрового позитивного потенциала малого бизнеса на основе выявленных ценностных ориентиров разных субъектов этого бизнеса мегаполиса.
\end{abstract}

Ключевые слова: мегаполис, малый бизнес, рынок труда, работодатели, наемные работники, условия труда, интересы

Введение. В условиях современного мегаполиса, при растущей атомизации общества, проявляющейся в нарастающей замкнутости, индивидуализме и потребительском отношении граждан друг к другу, приоритетом становятся ориентиры, направленные на удовлетворение личных интересов и потребностей. Со временем трансформация сознания жителей мегаполиса в данном вопросе приобретает все более очевидный характер.

В настоящее время на рынке труда малого бизнеса г. Москвы разрешение проблемы трудовых интересов зачастую переходит в плоскость игнорирования возможных компромиссов в тандеме «работник - работодатель». Не последнюю роль здесь играет избыточная концентрация активной рабочей силы в локальных территориях страны.

Тенденция увеличения численности крупных городов за счет притока человеческих ресурсов с периферии происходит во многих странах мира. 
Крупнейшим центром финансового и трудового потенциала в России стала Москва. Несмотря на официальную статистику численности населения столицы России, некоторые аналитики, ссылаясь на различные методы подсчетов населения мегаполиса, говорят о цифрах в 25 и даже 27 млн чел. ${ }^{1}$ Причем эксперты подсчитали, что в Москве проживают $54 \%$ приезжих 2 .

Привлекательность мегаполисов для трудовых мигрантов по-прежнему остается очень высокой, что, в свою очередь, обеспечивает постоянную восполняемость ресурсов для предприятий малого бизнеса. Интенсивность притока внутренних и внешних трудовых мигрантов в Москву позволяет работодателю долгое время не предпринимать действия, направленные на улучшение условий труда и индексацию заработной платы сотрудников. В результате этого сотрудники, не согласные с предложенными условиями труда, вытесняются более лояльными работниками, прибывающими в мегаполис для реализации своих целей. Так, согласно исследованию, в 2018 г. из 7,2 млн рабочих мест, функционировавших в Москве, 3 млн занимали трудовые мигранты. Кроме того, исследователи пришли к выводу, что почти каждый второй москвич из числа экономически активного постоянного населения столицы в 2018 г. не смог найти себе работу 3 .

Методология и методы. Основой исследования выступает комплексный анализ функционирования малого бизнеса в условиях Москвы с позиции экономико-социологического подхода. Авторы проводят анализ отечественных работ по теме исследования. Эмпирическая база исследования представлена в форме авторского анкетного социологического опроса референтной группы (работодатели и наемные работники малого бизнеса Москвы, $N=156$ ), проведенного в период с апреля по июнь 2021 г. в 4 административных округах г. Москвы выборочным методом.

Результаты и обсуждение. Анализ структуры малого бизнеса выявил особенности ее формирования на основе социально-демографических и профессиональных характеристик вовлеченных социальных групп. Среди них определяющими являются возраст, наличие навыков и опыта работы, готовность к труду на предлагаемых условиях, самовосприятие своего жизненного статуса.

Качественный состав любой социальной группы зависит от наличия сотрудников, обладающих высокими профессиональными качествами, такими как образование, опыт, ценность (уникальность). Наиболее ценными сотрудниками в данных сферах считаются те, кто обладает существенными коммерческими коммуникациями в деловой среде. В то же время практически не рассматриваются такие немаловажные качества специалиста, как культура поведения и наставничество. Доля креативных исполнителей, обладающих высокой мотивацией и важным набором профессионально-личностных качеств, по мнению работодателей и наемных работников, остается на низком уровне. Первопричину такого положения работодатели видят в нехватке специалистов, а работники - в их избытке. Так, более $2 / 3$ опрошенных работников малого бизнеса отмечали излишнее число в организациях специалистов с дублирующими функциями.

1 Козуров Д. 2020. Исследование: в Москве живет в два раза больше людей, чем по официальной статистике. - Комсомольская правда. 17.02.2020. С. 1. Доступ: https://www. kp.ru/daily/27092/4165568/ (проверено 12.12.2021).

2 Переезд россиян и москвичей в другой регион страны. - Агентство городских новостей «Москва». 30.11.2020. Доступ: https://www.mskagency.ru/materials/3064907 (проверено 12.12.2021).

3 Игры с цифрами: сколько москвичей на самом деле не имеют постоянной работы. Новые Известия. 26.04.2019. Доступ: newizv.ru/article/general (проверено 12.12.2021). 
Качественный состав социальных групп малого бизнеса зачастую выстроен под проекты с максимально быстрой окупаемостью без учета профессионально-психологических качеств взаимодействующих сотрудников, что не может не отражаться на общей корпоративной культуре организации, уровне предоставляемых ею услуг. Малый бизнес Москвы замкнулся в определенных рамках кадровой селекции: предпочтение отдается гражданам, отличающимся высокой лояльностью и непритязательностью в условиях и оплате труда. По-прежнему в основе возобновления кадров выступает ресурсный потенциал регионов: от $46 \%$ до $78 \%$ сотрудников составляют приезжие граждане из других субъектов РФ и ближнего зарубежья.

В свою очередь, сильное социальное расслоение в материальных доходах, высокая закредитованность, семейно-родственные обязательства, а также страх потери трудовых доходов заставляет многих работников держаться за свои рабочие места. Все это отражается на рынке труда: в период с 2009 по 2020 г., согласно аналитикам сайта SuperJob, процент граждан, готовых работать по серой зарплате, практически не падал ниже $40 \% 1$.

По результатам авторского социологического опроса было установлено, что доля опрошенных респондентов, не удовлетворенных настоящей трудовой деятельностью, оказалась более 54\%. Результаты ответов на вопрос: «Что Вас удерживает на данной работе?» - приведены на рис. 1.

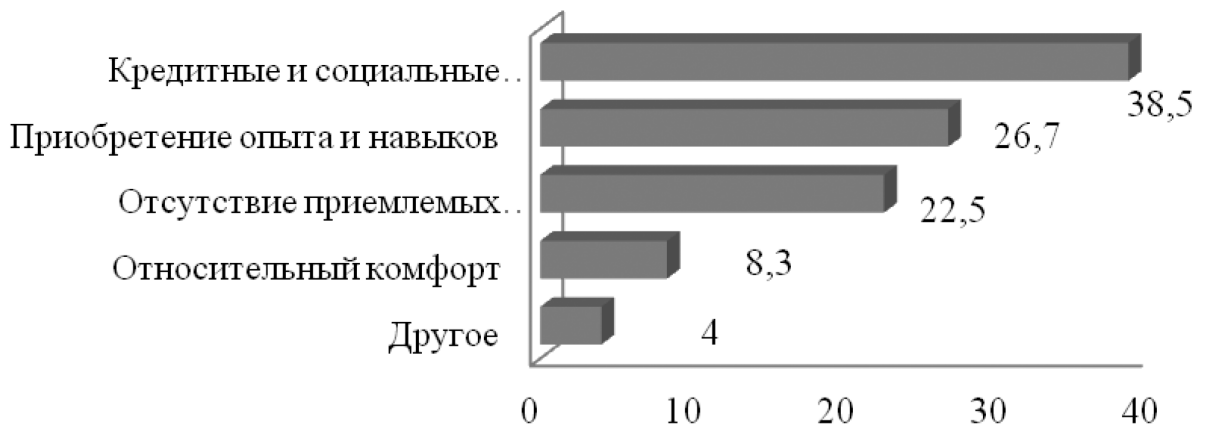

Рисунок 1. Результаты ответов на вопрос: «Что Вас удерживает на данной работе?», в \% от числа ответивших $(N=156)$

Как видно из рис. 1, среди наиболее часто употребляемых ответов на данный вопрос были:

- кредитные (жилищные, потребительские и др.) и социальные (оказание материальной помощи в обеспечении, обучении, лечении близких родственников) обязательства;

- необходимость приобретения требуемого опыта и навыков работы;

- отсутствие приемлемых альтернатив;

- относительный комфорт (рабочий коллектив, транспортная доступность).

Ключевой составляющей вовлеченности персонала является забота о своих подчиненных, проявленная руководством компании. По результатам опроса аналитиков крупнейшей российской компании интернет-рекрутмента HeadHunter (hh.ru) 47\% соискателей оценили заботу своих работодате-

1 Россияне стали чаще соглашаться на черную зарплату. - Исследовательский центр Superjob.ru. 16.12.2020. Доступ: https://www.superjob.ru/research/articles (проверено 12.12.2021). 
лей достаточно низко, причем основной вид заботы руководства, по словам респондентов (70\%), проявляется в вовремя выданной сотрудникам зарплате. Примечательно, что при должном внимании руководства подавляющее большинство сотрудников московских фирм (89\%) готовы выполнять сверхурочную работу 1 .

В большинстве компаний малого бизнеса преобладает многофункциональный подход в работе сотрудника - включенность его во многие функциональные обязанности в целях минимизации затрат рабочего процесса. Отсюда выше динамика работы, уровень стресса и утомляемость персонала.

Ряд экспертных оценок, затрагивающих зарплатные ожидания москвичей и уровень комфортного проживания в столице, показывают, что при средней зарплате «сотрудникам на позициях "ведущий специалист/специалист" столичные компании готовы платить около 100 тысяч рублей», что в условиях постоянного темпа роста цен на многие товары и услуги выглядит явно недостаточно. При этом эксперты оценивают комфорт жителей мегаполиса, исходя из возможностей решения их жилищного вопроса ${ }^{2}$.

На основании полученных данных в табл. 1 авторы представляют перечень наиболее значимых, с точки зрения работников, факторов, определяющих их вовлеченность в рабочий процесс, а также непосредственно влияющих на дальнейшие трудовые отношения.

Таблииа 1

\section{Социально-экономические факторы, определяющие комфортность трудовых} отношений

\begin{tabular}{|l|l|}
\hline \multicolumn{1}{|c|}{ Факторы } & \multicolumn{1}{c|}{ Наиболее значимые стороны } \\
\hline $\begin{array}{l}\text { Уровень материального } \\
\text { вознаграждения }\end{array}$ & $\begin{array}{l}\text { Зарплата, премия, социальные и стимулирующие } \\
\text { выплаты (бонусы) }\end{array}$ \\
\hline $\begin{array}{l}\text { Значимость трудовой } \\
\text { деятельности }\end{array}$ & $\begin{array}{l}\text { Престижность работы, степень вовлеченности в } \\
\text { работу, профессиональная мобильность, повышение } \\
\text { квалификации, принятие сферы деятельности, } \\
\text { внимание к профессиональному комфорту сотрудника }\end{array}$ \\
\hline Условия работы & $\begin{array}{l}\text { Транспортная доступность места работы, комфортность } \\
\text { рабочего места, распорядок рабочего дня и нагрузка } \\
\text { персонала, обеденный перерыв, график отпусков, } \\
\text { командировка и переработка, защита персонала, } \\
\text { уровень механизации и автоматизации в компании }\end{array}$ \\
\hline $\begin{array}{l}\text { Уровень корпоративной } \\
\text { культуры }\end{array}$ & $\begin{array}{l}\text { Микроклимат в коллективе, организация сплоченности } \\
\text { и досуга сотрудников }\end{array}$ \\
\hline
\end{tabular}

Источник: Выполнено на основании распределения ответов работников малого бизнеса (по данным авторского опроса 2017-2020 гг., $N=228$ чел.)

Как видим, наиболее значимым для сотрудников является материальный аспект, затем возможности профессионального роста, степень вовлеченности в работу. Уровнем корпоративной культуры, являющимся, безусловно, важным фактором в работе персонала, в настоящий момент многие работники готовы

${ }^{1}$ Как работодатели заботятся о сотрудниках. Опрос hh.ru от 24 апреля 2019 г. Доступ: https://hh.ru/article/24566?from=article_24862 (проверено 12.12.2021).

2 Ташевская Н. 2021. Жителям регионов назвали главные условия комфортного переезда в Москву. - Лента. 06.10.2021. С. 2. Доступ: https://lenta.ru/news/2021/10/06/msc_pereezd (проверено 12.12.2021). 
пренебречь при условии высоких материальных и нематериальных бонусов. Однако стоит отметить, что подобные приоритеты наблюдаются в основном у молодых сотрудников до 40 лет. Более старший контингент сотрудников после материального вознаграждения заинтересован в условиях труда и микроклимате в рабочем коллективе.

Многочисленные авторские исследования позволяют сформировать определенную модель оптимального функционирования работника при условии удовлетворения его основных потребностей: наличие жилья, работы, комфортной среды.

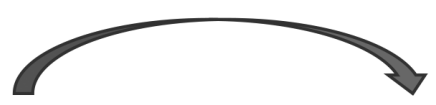

\section{Работа Жилье Комфортная среда}

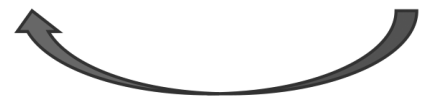

Источник: авторская разработка

Рисунок 2. Наиболее характерные условия оптимального функционирования работника

Не вдаваясь в размышления о первичности «работы» или «жилья» для индивидуума, предложим следующее: для иногороднего работника, не являющегося собственником жилья в регионе трудоустройства, вопрос проживания на первом этапе будет являться первостепенным, в то время как для местного жителя - вторичным. Однако вопрос улучшения комфорта в среде проживания и работы, как показывают результаты исследований, будет следующим этапом оптимального функционирования человека, в противном случае возникает задача по поиску более комфортной среды. Под комфортной средой мы будем понимать среду, отвечающую оптимальным для индивидуума социально-экономическим, эмоционально-духовным и другим условиям его функционирования.

Одним из основных направлений формирования благоприятной социокультурной среды для успешного трудового сотрудничества и взаимодействия в малом бизнесе является усиление работы, направленной на помощь активным гражданам в реализации своего потенциала. На основании трех наиболее важных показателей рабочего места, с точки зрения наемных работников, были составлены категории престижности работы.

Критерии для выделения категорий престижности работы:

1) заработная плата: высокая зарплата - от 120 тыс. руб. в месяц; средняя - от 80 тыс. руб. в месяц; низкая - менее 80 тыс. руб.;

2) условия труда: высокие - комфортное рабочее место, строгое соблюдение трудового законодательства, профессиональная вовлеченность и карьерный рост, наличие помещений для приема пищи, проведения занятий, переговоров (совещаний), релаксации, спорта и т.д.; средние - комфортное рабочее место, соблюдение трудового законодательства, профессиональная вовлеченность, наличие комнат для приема пищи, раздевалок и т.д.; низкие - не соответствующие средним условиям.

3) трудовые обязательства: высокие - жесткие требования к соблюдению трудового распорядка и функциональных обязанностей сотрудника; сред- 
ние - лояльные требования к соблюдению трудового распорядка и функциональных обязанностей сотрудника. Низкие требования трудовых обязательств работниками не рассматривались, что говорит об их стремлении к добросовестному труду. Высокий уровень трудовых обязательств, по мнению большинства соискателей, должен быть компенсирован соответствующими уровнями зарплаты и условиями труда, и наоборот, низкий уровень зарплаты или условий труда должны компенсироваться более лояльным трудовым распорядком.

Большинство респондентов находятся на должностях, отвечающих низким и крайне низким категориям престижности работы. Отсюда возникает необходимость говорить о социально непривлекательных вакансиях, к которым мы будем относить предложения о работе, не отвечающие заявленным интересам (требованиям) соискателей по материальному и социально-профессиональному критериям отбора. В общем случае - это вакансии, соответствующие работе ниже средней категории. Примечательно, что у соискателей в приоритете не столько соответствие вакансии их профессиональным качествам, сколько возможное материальное вознаграждение. Так, 2/3 респондентов готовы работать не по специальности при условии, что уровень их первоначальной заработной платы снизится не более чем на $20 \%$ от предыдущего заработка с возможностью дальнейшего роста. При этом проблема обнуления предыдущих профессиональных компетенций (стаж, навыки) в новой специализации переносится работником наиболее болезненно при нисходящей мобильности. Вынужденное движение вниз по лестнице социально-экономического статуса заставляет человека искать перспективы для себя и своих близких в новых социальных пространствах, отвечающих его представлению об оплате труда. Понижение социального статуса для большинства соискателей в процессе их трудовой деятельности возможно при условии увеличения материального вознаграждения и улучшения условий труда. При этом под улучшением условий труда зачастую подразумевается лояльность по отношению к трудовой дисциплине, снижение нагрузки и ответственности.

Как показывают результаты опросов, большинство работодателей, предлагающих вакансии по рабочим специальностям, мало интересует история профессиональной траектории сотрудника. В приоритете - его опыт, навыки, умения, адаптационные способности. Вторичными факторами выступают психологическая совместимость, социальная и правовая адаптации работников к рабочему месту. Одновременно с этим, руководствуясь преобладанием предложения над спросом, работодатели не стремятся менять ключевые факторы вакансии - условия оплаты и условия труда. В большинстве случаев уровень реальных выплат занижен в среднем на 15-20\% по сравнению с величиной предлагаемой стартовой зарплаты. Этому способствует очень большая доля наемного труда (90\% занятых) в России, и ее необходимо снижать для демократизации экономической деятельности [Голенкова, Игитханян 2015: 83].

Избыточная рабочая сила, появляющаяся в огромных количествах в результате деиндустриализации мегаполиса и уменьшения производственной деятельности его жителей, способствует появлению класса социально невостребованных и нереализованных наемных работников, обладающих избыточной компетенцией для занимаемой (предлагаемой) должности, не имеющих возможности для профессионального и личностного роста, реализации своего peсурса. В определенной степени этому способствует процесс глобализации, который, как утверждает Н.Н. Зарубина, оторван по характеру своей деятельности от культурно-национальных интересов [Зарубина 2021: 9]. В результате у работодателей появляется свобода от ряда социальных обязательств, 
например, отпадает необходимость улучшения условий труда сотрудников. Постоянная циркуляция трудовых потоков позволяет диктовать требуемую кадровую селекцию персонала.

Между тем для категории граждан, работающих не по призванию, а под воздействием внешних обстоятельств, оптимальным является развитие своего профессионального потенциала. В данном вопросе государственным органам необходимо максимально задействовать интеллектуальный ресурс жителей мегаполиса, внедрив широкие возможности доступных программ переподготовки для наиболее квалифицированной и мотивированной категории граждан.

Так, по оценкам экспертов, спрос в Москве на специалистов IT-направления превышает предложение почти в 22 раза $^{1}$. Но для полноты картины необходимо рассмотреть соотношение спроса и предложения рабочих мест, составленное авторами в декабре 2021 г. на основе данных популярного сайта интернет-рекрутмента hh.ru по г. Москве и Московской обл. Согласно приведенным в табл. 2 данным, число предложений (резюме) превышает спрос (вакансии) в 17,5 раз в Москве и в 11 раз - по Московской обл. Наибольшее превышение предложения над спросом наблюдается у юристов - в 61,5 раз; у бухгалтеров в 54,2 раза; у водителей - в 44,1 раза; у менеджеров по продажам - в 39,9 раз.

Подобный дисбаланс на рынке труда, помимо всего прочего, объясняется тем, что число активных резюме отражает не число безработных соискателей в регионе, но число соискателей, заинтересованных в более комфортных условиях труда. Таким образом, говорить необходимо не о «дефиците кадров», а о «дефиците комфортного труда», т.е. труда, который отвечает современным условиям в плане безопасности, привлекательности и комфортности рабочей среды.

Таблица 2

Соотношение спроса и предложения работы в Москве и Московской области в 2021 r.

\begin{tabular}{|l|c|c|c|c|}
\hline \multirow{2}{*}{ Наименование вакансий } & \multicolumn{2}{|c|}{ Число вакансий, тыс. } & \multicolumn{2}{c|}{ Число резюме, тыс. } \\
\cline { 2 - 5 } & в Москве & в Московской обл. & в Москве & в Московской обл. \\
\hline Всего & 162,66 & 65,08 & 2830,15 & 714,2 \\
\hline из них: & & & & \\
\hline $\begin{array}{l}\text { программист и специалист } \\
\text { ІТ-индустрии }\end{array}$ & 24,57 & 2,06 & 218,87 & 28,85 \\
\hline менеджер по продажам & 12,24 & 3,98 & 488,77 & 116,22 \\
\hline продавец-консультант & 6,74 & 4,19 & 200,24 & 71,16 \\
\hline бухгалтер & 6,50 & 1,59 & 352,42 & 92,08 \\
\hline водитель & 6,12 & 5,07 & 270,03 & 88,69 \\
\hline продавец-кассир & 5,97 & 5,05 & 146,15 & 59,86 \\
\hline врач & 5,32 & 2,00 & 63,73 & 12,04 \\
\hline рабочий & 4,57 & 3,72 & 23,56 & 8,16 \\
\hline повар & 2,53 & 1,00 & 74,08 & 19,44 \\
\hline юрист & 2,48 & 0,42 & 152,76 & 31,34 \\
\hline
\end{tabular}

Источник: сайт по поиску работы и сотрудников hh.ru. Доступ: https://hh.ru/search/ vacancy?area $=1 \&$ fromSearchLine (проверено 27.12.2021).

1 Центр «Моя работа» рассказал о самых востребованных профессиях весны 2021. Апрель 2021 г. Доступ: https://dszn.ru/press-center/news/6190 (проверено 27.01.2022). 
Действительно, несмотря на то что одними из востребованных профессий на рынке труда Москвы в 2021 г. по-прежнему являются рабочие специальности (строители, сантехники, электрики, автослесари, операторы и т.п.) ${ }^{1}$, средний предлагаемый заработок устраивает лишь каждого пятого соискателя рабочего места ${ }^{2}$.

Подобная самобытность развития рынка труда столицы поддерживается самими работодателями: зачастую максимизация прибыли компании осуществляется посредством освобождения бизнеса от национальной привязки, а оптимизация производственных процессов - в ущерб их новаторству и модернизации. Не случайно по итогам 2020 г. Москва поднялась лишь на 32-е место в рейтинге 100 ведущих инновационных кластеров мира (анализ числа заявок на патенты и числа научных публикаций $)^{3}$. Уместно заметить, что процесс инновации идет неразрывно с наличием необходимых условий для его осуществления. В первую очередь локомотивами инноваций являются талантливые граждане. По показателю привлекательности бизнеса Москва в рейтинге городов мира находится на 42-м месте 4 .

Сделаем некоторые выводы. Создание благоприятных условий для трудовой и образовательной деятельности субъектов малого бизнеса в г. Москве требует еще значительных усилий. Социально-экологическая обстановка, культурнонравственный уровень граждан, а также степень соблюдения их прав формируют базу показателей прогрессивного развития общества, игнорирование которых приводит к ощущению беззащитности и апатии. Низкая возможность самореализации и вовлеченности людей в процессы сопричастности к развитию страны ослабляет в человеке чувство социальной востребованности, развиваясь сначала в апатию, а затем - в социальную напряженность в обществе.

Для увеличения делового потенциала экономически активного населения необходимо обеспечить в материальном плане право реализации ими образовательных программ посредством образовательных ваучеров - оплаченных государством краткосрочных курсов (учебных часов) по переподготовке наиболее социально и профессионально востребованных профессий, в первую очередь в области инжиниринга и программирования. Приоритетный контингент - мотивированные граждане, имеющие необходимое базовое образование для успешного прохождения курсов переподготовки.

Малый бизнес отражает в первую очередь уровень кадрово-управленческой, финансовой грамотности и профессиональной компетенции его руководства. Главное качество современного владельца малого бизнеса - стратегическое мышление по продвижению бизнеса, а также способность сформировать работающую команду сотрудников и уникальность предлагаемых на рынке товаров или услуг.

\footnotetext{
1 Рынок труда Москвы адаптировался: вакансий больше, чем до пандемии. Аналитическая справка РБК от 31 мая 2021 г. Доступ: https://www.rbc.ru/society/ (проверено 12.12.2021).

2 День энергетика: спрос на работников вырос на 54\%, а зарплата - лишь на 9\%. Итоги года в отрасли по версии hh.ru от 22 декабря 2021 г. Доступ: https://hh.ru/article/29753 (проверено 12.12.2021).

3 The Global Innovation Index (GII) 2020. URL: https://www.globalinnovationindex.org/ userfiles/file/reportpdf/GII_2020_KeyFindings_RU_web.pdf (accessed 12.12.2021).

4 The 2019 Global Talent Competitiveness Index. URL: https://www.insead.edu/news/2019global-talent-competitiveness-index-nurturing-entrepreneurial-talent-identified-as-key-tocompetitiveness (accessed 12.12.2021).
} 


\section{Список литературы}

Голенкова 3.Т., Игитханян Е.Д. 2015. Социальная динамика наемных работников в России. - Вестник РУДН. Сер. Социология. № 2. С. 80-92.

Зарубина Н.Н. 2021. Экономическая социология. М.: Юрайт. 378 с.

NIKONOV Vladimir Aleksandrovich, postgraduate student at the Institute of Sociology - Branch of the Federal Center of Theoretical and Applied Sociology, Russian Academy of Sciences (bld. 5, 24/35 Krzhizhanovskogo St, Moscow, Russia, 117218; nikon561@yandex.ru)

VORONOV Victor Vasil'evich, Dr.Sci. (Soc.), Professor; Leading Researcher at the Institute of Sociology - Branch of the Federal Center of Theoretical and Applied Sociology, Russian Academy of Sciences (bld. 5, 24/35 Krzhizhanovskogo St, Moscow, Russia, 117218 voronov@isras.ru)

\section{SMALL BUSINESS IN MOSCOW AND CHANGES IN THE LABOR ATTITUDES OF ITS PARTICIPANTS}

\footnotetext{
Abstract. The article, from the standpoint of economic sociology, carries out the analysis of the contradictory interests of employers and employees to working conditions in small business on the example of a megalopolis. A number of unfavorable trends in the field of labor relations have been established, associated with the low interest of employees in non-prestigious activities, their low involvement in these relations while ignoring their interests on the part of employers. The authors substantiate the necessity of a rational approach to the complex process of forming the personnel positive potential of small business on the base of the identified value orientations of various subjects of this megalopolis business.

Keywords: megalopolis, small business, labor market, employers, employees, working conditions, interests
} 